Hydrology and Earth System Sciences, 9(6), 607-613 (2005) C EGU

\title{
The impact of broadleaved woodland on water resources in lowland UK: \\ II. Evaporation estimates from sensible heat flux measurements over beech woodland and grass on chalk sites in Hampshire
}

\author{
John Roberts ${ }^{1}$, Paul Rosier ${ }^{1}$ and D. Mark Smith ${ }^{2}$ \\ ${ }^{1}$ Centre for Ecology and Hydrology, Wallingford, OX10 8BB, UK \\ 27 Brodick Drive, East Kilbride, G74 4QU, UK \\ Email for corresponding author: jro@ceh.ac.uk
}

\begin{abstract}
The impact on recharge to the Chalk aquifer of substitution of broadleaved woodland for pasture is a matter of concern in the UK. Hence, measurements of energy balance components were made above beech woodland and above pasture, both growing on shallow soils over chalk in Hampshire. Latent heat flux (evaporation) was calculated as the residual from these measurements of energy balances in which sensible heat flux was measured with an eddy correlation instrument that determined fast response vertical wind speeds and associated temperature changes. Assessment of wind turbulence statistics confirmed that the eddy correlation device performed satisfactorily in both wet and dry conditions. There was excellent agreement between forest transpiration measurements made by eddy correlation and stand level tree transpiration measured with sap flow devices. Over the period of the measurements, from March 1999 to late summer 2000, changes in soil water content were small and grassland evaporation and transpiration estimated from energy balance-eddy flux measurements were in excellent agreement with Penman estimates of potential evaporation. Over the 18 month measurement period, the cumulative difference between broadleaved woodland and grassland was small but evaporation from the grassland was 3\% higher than that from the woodland. In the springs of 1999 and 2000 , evaporation from the grassland was greater than that from the woodland. However, following leaf emergence in the woodland, the difference in cumulative evaporation diminished until the following spring.
\end{abstract}

Keywords: land use, water resources, broadleaved woodland, grass, evaporation, drainage

\section{Introduction}

In predicting the likely impact of woodland planting on water resources by comparing the water use of woodland versus grass, one of the difficulties is the conflicting evidence from previous experiments. Some studies have demonstrated a substantially greater water use by woodland (Calder et al.,1997, 2000) whilst others have shown little difference (Harding et al., 1992; Roberts and Rosier 2005b).

In Roberts and Rosier (2005a), soil water content and soil water potential data were used to reconfirm that drainage can still be occurring in chalk below mineral soils in which significant negative soil water potentials have developed. Daily evaporation data, obtained by an energy balance approach, together with rainfall data and changes in soil water content in a water balance formulation, showed that, although there are seasonal differences, on an annual basis, the drainage below broadleaved woodland at Black Wood did not differ significantly from that below pasture at Bridgets Farm.

This paper describes the energy balance measurements made at Black Wood and Bridgets Farm, as well as various estimates of evaporation provided by the energy balance approach and some comparisons using alternative datasets to support and give confidence in the energy balance measurements.

\section{Methods}

SITES

The experimental sites in a beech woodland and in permanent pasture were described in Roberts and Rosier 
(2005a). The specific details presented here refer to the energy balance measurements made at those two sites from March 1999 to September 2000.

\section{MEASUREMENTS}

Evaporation estimated from measurements of the energy balance

The surface energy balance can be stated as:

$$
R_{n}+G+H+\lambda E+S=0
$$

where $R_{\mathrm{n}}$ is the net radiation, $G$ is the soil heat flux, $H$ is the sensible heat flux, $\lambda E$ is the latent heat flux (evaporation) and $S$ represents heat storage in the biomass and within the canopy air space. Changes in biomass storage on a diurnal basis are likely to be significant at Black Wood and would be required for precise hourly estimates of latent heat flux. For the present purpose, any changes in heat storage remain as a residual along with estimates of the latent heat flux. However, over periods of 24 hours, both negative and positive changes in heat storage in the biomass and air space (i.e. $S$ ) tend to cancel out and the energy balance equation then reduces to:

$$
R_{n}+G+H+\lambda E=0
$$

For clarification, it should be noted that evaporation includes transpiration, i.e. water taken from the soil and lost from the foliage during dry weather as well as evaporation of surface water from leaves wetted by rain or dew and evaporation from the underlying soil and litter layer. In winter, any evaporation from the forest in dry conditions will actually be from the litter layer drying out.

\section{Black Wood}

An automatic weather station (AWS) (Didcot Instrument Company Ltd., Abingdon, UK), mounted on a $28.4 \mathrm{~m}$ high aluminium sectional tower in the forest, comprised a solarimeter, a wet and dry bulb thermometer in a ventilated psychrometer screen, an anemometer and a wind direction sensor. On a separate pole was a funnel $\left(314 \mathrm{~cm}^{2}\right.$ in area) from which rainfall was directed by a polythene tube to a tipping bucket rain gauge $\left(0.5 \mathrm{~mm} \mathrm{tip}^{-1}\right)$ on the forest floor. Measurements from the AWS instrumentation were recorded hourly on a datalogger (Model CR10 logger, Campbell Scientific Ltd., Shepshed, UK). Mounted on a lightweight aluminium boom on the south side at the top of the tower was a net radiometer (Model Q-7, REBS, Seattle, Washington, USA), located far enough away from the structure of the tower to ensure that radiation detected by the lower section of the net radiometer did not include any reflections from the tower.

Sensible heat flux was calculated from measurements of fluctuations in the vertical wind speed and the associated fluctuations in air temperature. The fluctuations in vertical windspeed were determined using a 'Solent' Model A1012R three-dimensional sonic anemometer (Gill Instruments, Lymington, UK) installed on top of the instrument tower $7.3 \mathrm{~m}$ above the main tree canopy. Air temperature within the pathways of the sonic anemometer was determined with a fine thermocouple (Model EMQSS M025E-300, Omega Engineering Ltd., Manchester, UK). The sampling rate of the anemometer and thermocouple was $5 \mathrm{~Hz}$ and the data were stored on a datalogger (Model CR21X, Campbell Scientific Ltd., Shepshed, UK). Derivation of sensible heat fluxes from the measurements assumed the principle of eddy covariance in which upward and downward moving eddies transport heat to or from the surface of the vegetation (Gash et al., 1999). As well as providing information on the fluctuations in the horizontal and vertical windspeed components, data from the sonic anemometer can be used to provide information on the momentum flux, or friction velocity, $u_{*}$.

Soil heat flux measurements by two soil heat flux plates (Model HFP01, Hukseflux Thermal Sensors, Delft, The Netherlands) were stored in the datalogger (Model CR10, Campbell Scientific Ltd., Shepshed, UK), which also recorded data from an AWS located on the forest floor. This AWS incorporated two net radiometers, wet and dry bulb thermometers in a ventilated psychrometer screen and an anemometer. The datalogger also recorded the tips from two tipping buckets associated with a plastic sheet net rainfall gauge.

The estimation of evaporation (Eqns. 1 and 2) combines information from eddy covariance measurements i.e. the 'Solent' anemometer, and the energy balance; this approach is referred to as the Solent/energy balance.

\section{Bridgets Farm}

A three-dimensional sonic anemometer, thermocouple and logging system, identical to that at Black Wood, was installed in the same plot as the Solent anemometer in the middle of Delaware field at Bridgets Farm. The anemometer was on a pole $2.5 \mathrm{~m}$ high in a $5 \times 5 \mathrm{~m}$ plot surrounded by electric fences. At no time did the grass in the field exceed $0.1 \mathrm{~m}$ in height. Data from the anemometer and thermocouple were recorded as 30-minute averages on a datalogger (Model CR21X, Campbell Scientific Ltd., Shepshed, UK). In the same plot, net radiation was measured with two net radiometers (Model Q-7, REBS, Seattle, Washington, USA) and soil heat flux with two soil heat flux plates (Model HFP01, Hukseflux Thermal Sensors, Delft, The 
Netherlands). The data from these sensors were recorded as hourly averages on a datalogger (Model CR10, Campbell Scientific Ltd., Shepshed, UK).

Hourly records from an AWS (Didcot Instrument Company, Abingdon, UK) administered by ADAS Bridgets, located $500 \mathrm{~m}$ to the south-east from the instrumentation in Delaware field, were used to estimate potential evaporation (Penman, 1948).

\section{Tree transpiration from sap flow}

Tree transpiration using the sap flow method (Roberts et al., 2001) was measured using 30 Granier thermal dissipation probes (TDP30 and TDP80, Delta-T Devices, Newmarket, UK) inserted into ten trees at any time during the leafy period of 1999 and 2000. These ten trees were instrumented for 14 days before the TDPs were transferred to a new set of trees. For all measurement periods, the ten trees selected were representative of the range of tree girth classes within the forest. Each group of instrumented trees occurred in a patch in the forest, from the area of which the individual tree transpirations were then scaled up to estimate transpiration on a ground area basis. From information on the tree stocking density, this value was scaled up to the forest stand.

Granier $(1985,1987)$ proposed a universal calibration for the output of TDPs against flow velocity but Granier's calibration coefficient proved to be inappropriate at Black Wood and a new calibration was determined using fresh beech logs through which known rates of water flow were generated (Roberts et al., 2001).

\section{Direct measurement of woodland floor evaporation}

Estimates of evaporation losses from the woodland floor were made in the spring of 1999 by weighing shallow trays $(220 \times 300 \times 40 \mathrm{~mm}$ deep) holding samples of the forest floor litter and the underlying humus and, in due course, of the understorey. The understorey comprised, predominantly, bluebells and, when these emerged, additional samples were necessary to determine woodland floor evaporation. Soil cores in which bluebells were growing were sampled into short $(120 \mathrm{~mm})$ sections of $150 \mathrm{~mm}$ diameter plastic drainage pipe. Both the trays and the plastic containers were fully wetted on the day before the evaporation measurements. On the measurement day, the trays were located on the forest floor and the plastic cylinders were relocated in the holes whence they had been sampled. Measurements were made hourly from dawn until dusk using a portable electronic balance.

\section{Results}

Performance of the Solent anemometer in wet and dry conditions

Sonic anemometers have been shown to operate just as effectively in wet as in dry conditions (Mizutani et al., 1997; Grelle et al., 1997; Gash et al., 1999). Both Grelle et al. (1997) and Gash et al. (1999) used the same type of sonic anemometer (Gill Solent, Model R2) as was used at Black Wood and Bridgets Farm.

Figure 1 plots standard deviations of vertical windspeed, $\delta_{\mathrm{w}}$ and the friction velocity, $u_{*}$ measured by the Solent anemometer on the tower in the forest at Black Wood. The analysis used hourly values in both wet and dry conditions; wet conditions were defined as at least $0.5 \mathrm{~mm}$ of rain in the hour. The similarity of the slopes of the plots of $\delta_{\mathrm{w}}$ and $u_{*}$ indicates that the sonic anemometer operates satisfactorily in both wet and dry conditions and that the upwind fetch for the instrument is satisfactory.

\section{Black Wood 1999}

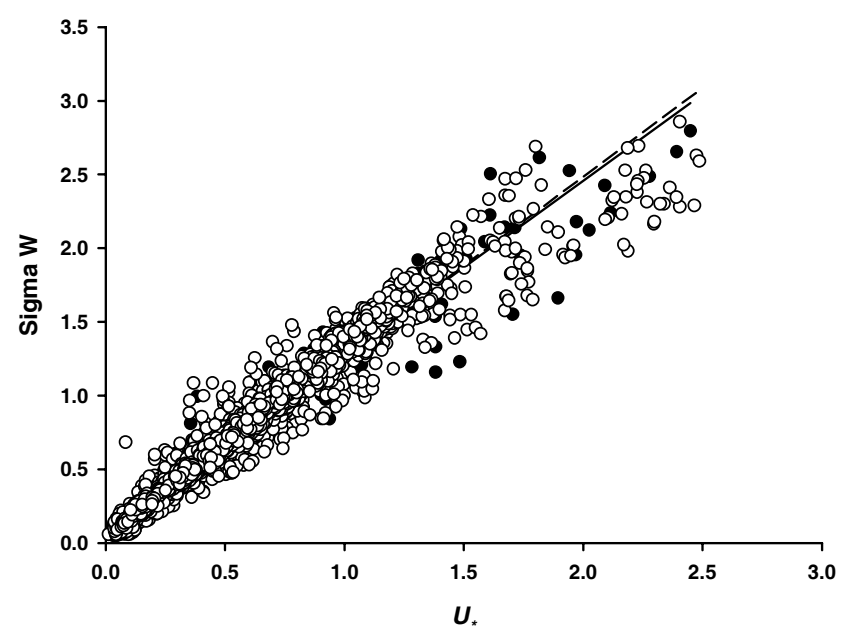

Fig. 1. Scatter diagram of the standard deviation of the vertical velocity fluctuations $\left(\delta_{w}\right)$ with the friction velocity $\left(\mathrm{u}_{*}\right)$ measured above the forest under dry (o) and rainy conditions ( $\bullet$ ). The regression lines and statistics for each data set are as follows: dry hours (---) slope $=1.207$, intercept $=0.070$ and $r^{2}=0.959$. Wet hours (-) slope $=1.174$, intercept $=0.107$ and $r^{2}=0.942$.

Cumulative evaporation losses from Black Wood and Bridgets Farm

Data for a comparison of evaporation from the two sites are available to calculate the energy balance at each from 10 March 1999 until 10 September 2000 when Delaware field at Bridgets Farm was ploughed. Data losses of around 7\% 


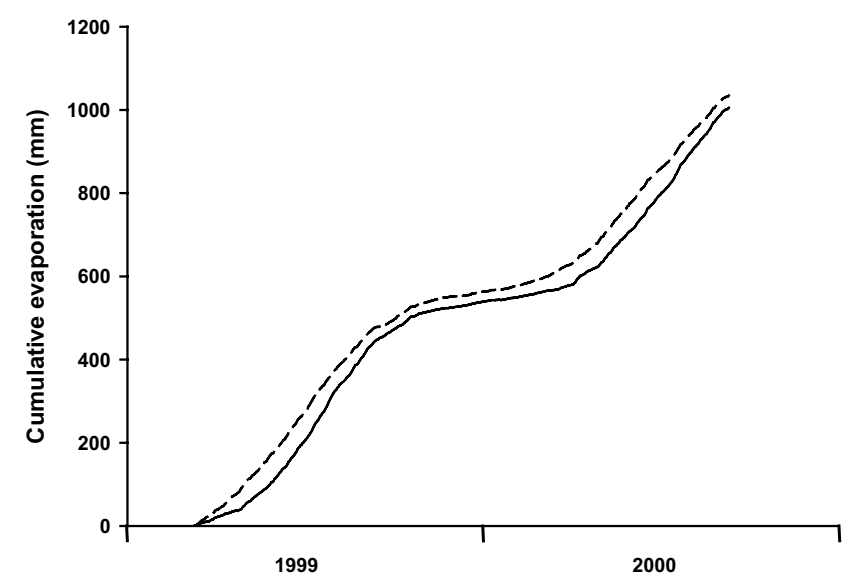

Fig. 2. Cumulative evaporation from Black Wood (-) and Bridgets Farm (---) estimated from Solent/energy balance.

occurred at both sites because of power supply failures or thermocouple breakages. An examination of the complete dataset showed that the latent heat flux was $70 \%$ of the net radiation at the particular site so any gaps in the evaporation estimates have been filled by this percentage of the net radiation. In fact, many of the occasions when data were lost were in winter and so this substitution was probably of little consequence to the annual totals.

The plot of cumulative evaporation fluxes from the two sites is given in Fig. 2. Over an approximately 18-month period, evaporation from Black Wood and Bridgets Farm is similar although that from Bridgets Farm is some 3\% greater. However, substantial differences do occur at other times. In the springs of both 1999 and 2000, before the emergence of leaves at Black Wood at the end of April, evaporation from Bridgets Farm is higher because of vigorous grass growth earlier in the spring. However, following leaf emergence at Black Wood, the difference in cumulative evaporation diminishes until the following spring.

Cumulative evaporation losses from Bridgets Farm and Penman evaporation

From the data available from the AWS operated by ADAS at Bridgets Farm, daily estimates of Penman potential evaporation were calculated for the period (March 1999 to September 2000) when the Solent/energy balance system was operating in the Delaware field at Bridgets Farm. Figure 3 compares the cumulative evaporation estimated by the Penman formula with measurements made with the Solentenergy balance system. Overall the agreement is excellent, with little indication of major seasonal discrepancies, except for a slight tendency for the actual evaporation to fall below potential evaporation in the late summers of both 1999 and

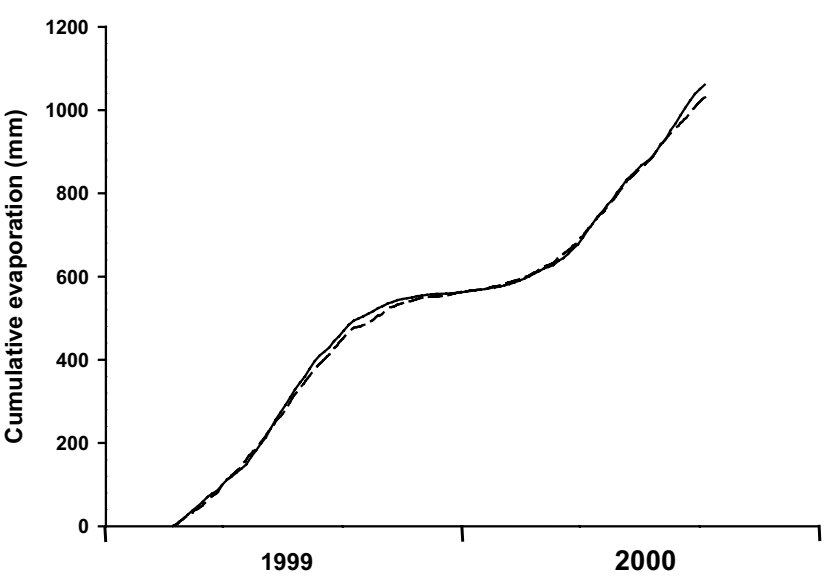

Fig. 3. Cumulative evaporation from Bridgets Farm estimated from Solent/energy balance (----) compared with Penman potential evaporation (-).

2000. However, at the end of the period the difference in the cumulative totals is less than $0.5 \%$.

Comparison of transpiration measured with sap flow and the Solent/energy balance determinations

Figure 4 compares daily transpiration measurements using thermal dissipation probes with the latent heat fluxes from the forest measured on the same day with the Solent/energy balance equipment. The days selected for this comparison were all dry and the beech trees at Black Wood were in leaf, between the end of April or early May and the end of October. The measurements show very good agreement, not only in absolute magnitude but also in the consistency of both their diurnal and seasonal patterns.

Direct measurements of forest floor evaporation Table 1 shows the daily values of litter evaporation in the spring of 1999 as well as estimates of transpiration from

Table 1. Evaporation rates of litter and transpiration from bluebells $\left(\mathrm{mm} \mathrm{day}{ }^{-1}\right)$ in the spring of 1999 at Black Wood. Values shown are the means and associated standard deviations from five determinations.

\begin{tabular}{lll}
\hline Date & Litter & Bluebells \\
\hline 16 January & $0.106+0.006$ & \\
17 January & $0.137+0.031$ & \\
31 January & $0.097+0.010$ & \\
13 February & $0.199+0.026$ & $0.662+0.108$ \\
28 February & $0.500+0.052$ & $0.939+0.290$ \\
13 March & $0.409+0.065$ & $1.212+0.373$ \\
18 April & $0.373+0.097$ & \\
\hline
\end{tabular}



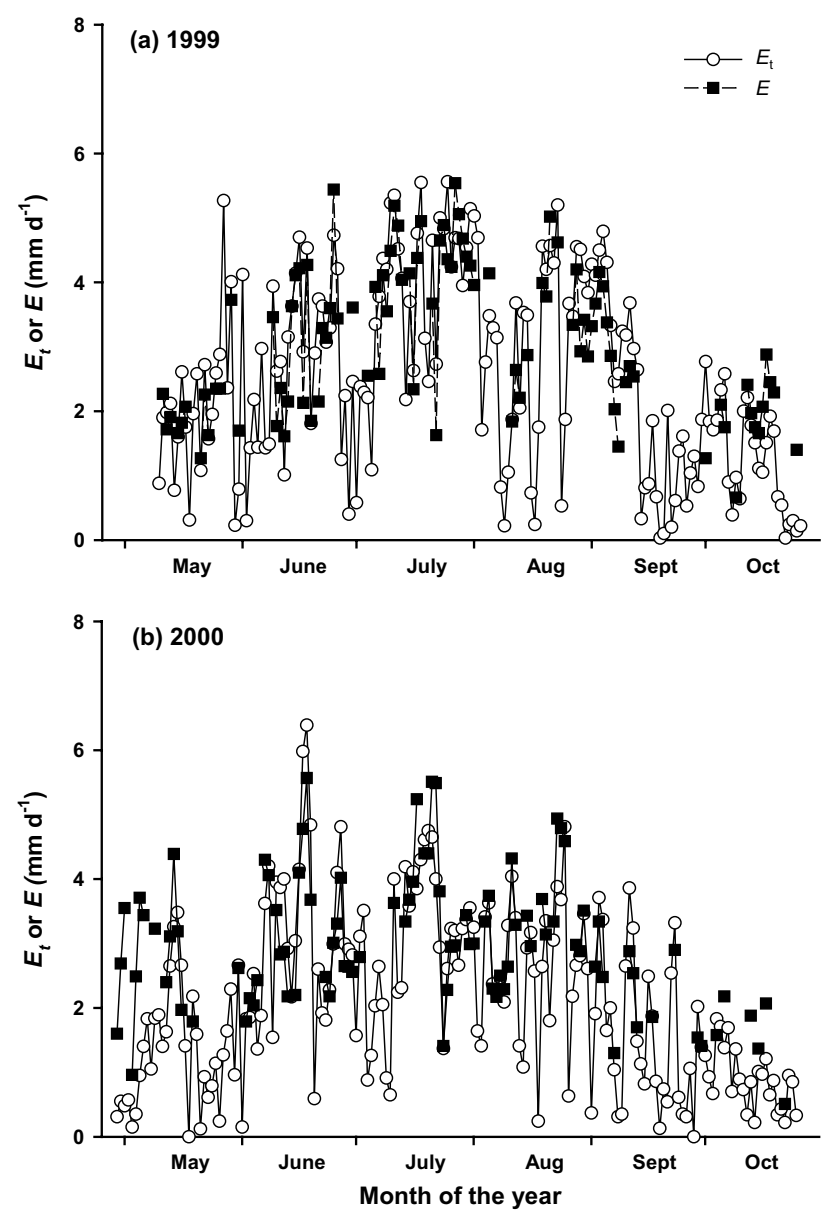

Fig. 4. Comparison of tree transpiration $\left(\mathrm{E}_{\mathrm{L}}\right)$ measured with thermal dissipation probes (0) and evaporation (E) on dry days using the Solent/energy balance equipment (-) in 1999 (a) and in 2000 (b).

bluebells. In January and early February, evaporation losses were small and monthly totals were less than $10 \mathrm{~mm}$ but, later in the spring, the losses from the litter increased to $0.5 \mathrm{~mm} \mathrm{day}^{-1}$ and the losses from the bluebells may increase the rate for the same conditions although the variance between litter estimates differed substantially from that from bluebells. On 13 March 1999, bluebells had appeared but were not fully developed and the evaporation measured by the Solent/energy balance system was $0.43 \mathrm{~mm}$. By 18 April, the bluebell understorey was fully developed but only in localised patches. On that day, the energy balance evaporation estimate was $0.45 \mathrm{~mm}$. Although full allowance cannot be made for the different flux sources, the estimates of losses from the litter compare well with the Solent/energy balance estimates.

\section{Discussion}

Roberts and Rosier (2005a) showed that latent heat flux data from Solent/energy balance systems located above the woodland at Black Wood and over grassland at Bridgets Farm, used in a water balance analysis, indicated that annual differences in drainage between the two land uses were small. Here, the latent heat fluxes from the two land uses were compared directly and, on an annual basis, evaporation from broadleaved woodland and grassland is similar.

Furthermore, various validation studies confirm that the Solent/energy balance systems have delivered acceptable results. The Solent anemometer has been demonstrated to work effectively in both wet and dry conditions and comparisons of evaporation from forest transpiration and grassland made using Solent/energy balance estimates were satisfactory.

The Solent R2 sonic anemometer used in these studies is calibrated such that significant errors can arise if fluxes associated with wind deviating from the horizontal by more than $30^{\circ}$ are encountered (Gash and Dolman, 2003; van der Molen et al., 2004). The error is likely to be larger in the measurement of fluxes over rough vegetation with high turbulence (i.e. forests in contrast to short vegetation) so that an underestimate of sensible heat fluxes of around 5 to $10 \%$ is likely. It follows that, because the measured sensible heat fluxes are used in an energy balance equation, the latent heat flux (i.e. evaporation), may be overestimated, particularly in the case of woodland. As the instantaneous raw data were not retained by the data logger, the fluxes cannot be recalculated with corrections for any cosine errors. Nevertheless, extrapolating the work of Gash and Dolman (2003) suggests that any corrections are likely to reduce the estimated evaporation flux from the woodland more than the grassland.

In the spring and early summer period, grass growth is particularly vigorous (Briggs and Courtney, 1989) but it is less so after midsummer so that the cumulative evaporation from the beech woodland converges with that from the grass. It is also in late summer that the actual evaporation from grass falls below (albeit very slightly) the Penman estimate of evaporation.

The excellent agreement between the Penman potential evaporation estimate and that from the Solent/energy balance system for grass under the circumstances of moisture availability that prevailed during the studies is not surprising. The net radiation term has a predominant role in both determinations. However, had evaporation from the grass been limited, for example, because a substantial soil water deficit had developed, the agreement might not have been so good.

During the studies reported here, there were no extended periods without rain and the grass did not appear to be stressed. The lack of water stress in the grass is an important contribution to the good agreement between the Penman 
estimate of evaporation and actual evaporation calculated as a residual in the energy balance. This situation contrasts radically with that reported by Wellings and Bell (1980) for the dry summer of 1976 at the same site. Then, actual evaporation was only about 0.75 of the Penman potential estimate. In contrast, in 1977 and 1978, actual evaporation agreed well with the Penman potential estimate. A parallel situation was observed with respect to drainage. In 1999 and 2000 drainage continued throughout the summer (Roberts and Rosier, 2005a) whereas at Bridgets Farm in 1976 , and in the following summer, drainage below the grass ceased from the profile observed around the middle of the year.

Calder et al. (1997, 2000) and Harding et al. (1992) produced models of evaporation for broadleaved woodland. A comparison of the output of these models with actual measurements of evaporation from Black Wood using the Solent/energy balance approach showed that, for both 1999 and 2000 (Fig. 5a and b) both models overestimated the

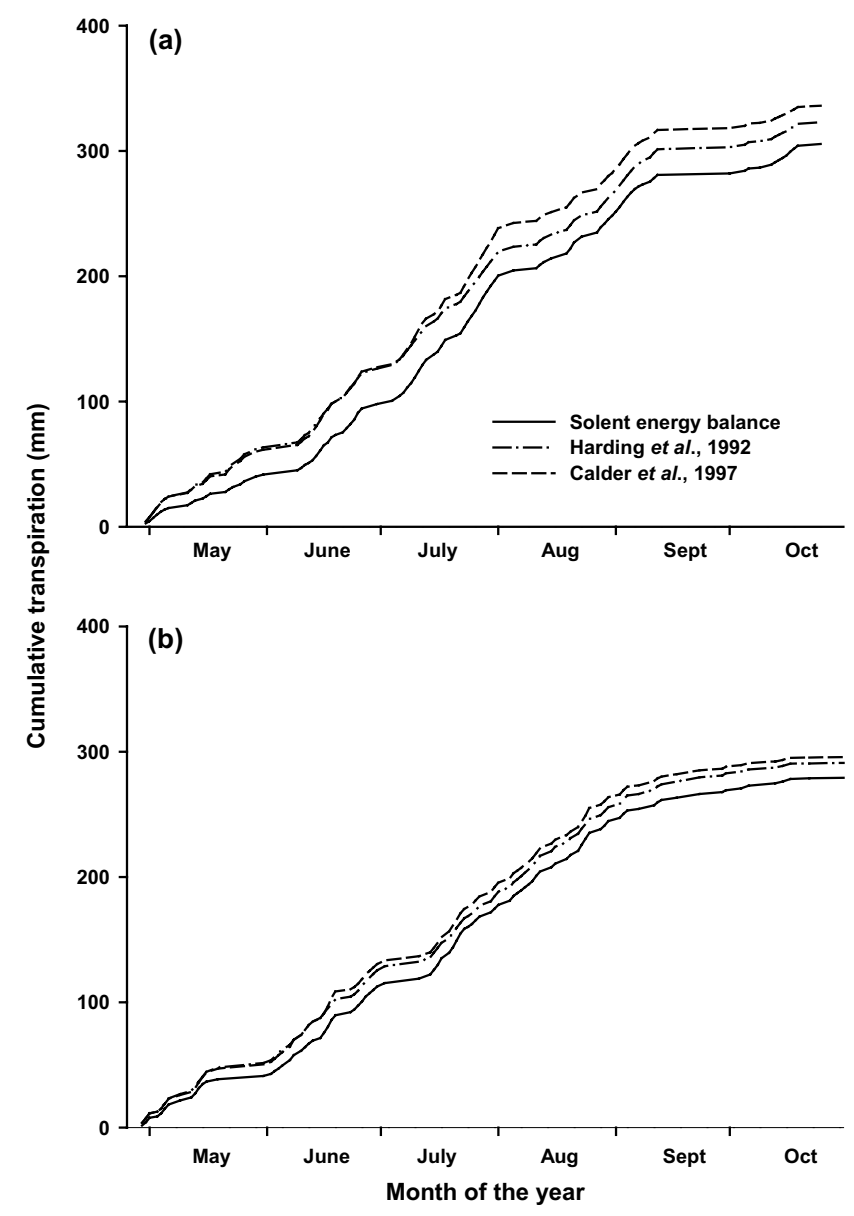

Fig. 5. Comparison of measurements of evaporation from the woodland at Black Wood made using the Solent/energy balance system (-) on dry days in the leafed periods in 1999 (a) and 2000 (b) with estimates from the models of Harding et al., 1992 (-.-.-.-) and Calder et al., 1997 (-----). transpiration as well as the interception components of evaporation, with the Calder et al. model overestimating more than the Harding et al. model.

\section{Acknowledgements}

The work described in this paper was funded partly from a contract (CWO 827) from the UK Department of the Environment, Transport and the Regions with additional financial support from the UK Environment Agency. The authors are very grateful to Alistair Culf for help in initiating the Solent anemometer sensible heat flux measurements and to the Forestry Commission and ADAS Bridgets for access and use of the experimental sites.

\section{References}

Briggs, D.J. and Courtney, F.M., 1989. Agriculture and Environment: the physical geography of temperate agricultural systems. Longmans, London, UK. 442pp.

Calder, I.R., Reid, I., Nisbet, T.R., Robinson, M. and Walker, D., 1997. TADPOLE, Trees and drought project on lowland England. Scoping study report to the UK Department of the Environment, March 1997.

Calder, I.R., Reid, I., Nisbet, T.R., Brainard, J., Green, J. and Walker, D., 2000. Impact of lowland community forests on groundwater resources. Proc. British Hydrological Society, $7^{\text {th }}$ National Hydrology Symposium, Newcastle, UK. 2.83-2.88.

Gash, J.H.C. and Dolman, A.J., 2003. Sonic anemometer (co)sine response and flux measurement I. The potential for (co)sine error to affect sonic anemometer-based flux measurements. Agr. Forest Meteorol., 119, 195-207.

Gash, J.H.C., Valente, F. and David, J.S., 1999. Estimates and measurements of evaporation from wet, sparse pine forest in Portugal. Agr. Forest Meteorol., 94: 149-158.

Granier, A., 1985. Une nouvelle méthode pour la mesure de flux de sève brute dans le tronc des arbres. Ann. Sci. Forest., 42, 193-200.

Granier, A., 1987. Evaluation of transpiration in a Douglas-fir stand by means of sap flow measurements. Tree Physiol., 3, 309-320.

Grelle, A., Lundberg, A., Lindroth, A., Moren, A.- S. and Ciencala, E., 1997. Evaporation components of a boreal forest: variations during the growing season. J. Hydrol., 197, 70-87.

Harding, R.J., Hall, R.L., Neal, C., Roberts, J.M., Rosier, P.T.W. and Kinniburgh, D.G., 1992. Hydrological impacts of broadleaf woodlands: Implications for water use and water quality. Project Report 115/03/ST, National Rivers Authority, Bristol, UK.

Mizutani, K., Yamanoi, K., Ikeda, T. and Watanabe, T., 1997. Applicability of the eddy correlation method to measure sensible heat transfer to forest under rainfall conditions. Agr. Forest Meteorol., 86, 193-203.

Penman, H.L., 1948. Natural evaporation from open water, bare soil and grass. Proc. Roy. Soc., A, 193, 120-146.

Roberts, J.M., Rosier, P.T.W. and Smith, D.M., 2001. Effects of Afforestation on Chalk Groundwater Resources. Final Report on Project CWO827 to UK Department of the Environment, Transport and the Regions. 81pp. 
Roberts, J.M. and Rosier, P.T.W., 2005a. The impact of broadleaf afforestation on water resources in lowland UK: I. A comparison of soil water changes below beech woodland and grass on chalk sites in Hampshire. Hydrol. Earth Syst. Sci., 9, 586-596.

Roberts, J.M. and Rosier, P.T.W., 2005b. The impact of broadleaf afforestation on water resources in lowland UK: III. The results from Black Wood and Bridgets Farm compared with those from other woodland and grassland sites. Hydrol. Earth Syst. Sci., 9, 604-610. van der Molen, M.K., Gash, J.H.C. and Elbers, J.A., 2004. Sonic anemometer (co)sine response and flux measurement II. The effect of introducing an angle of attack dependent calibration. Agr. Forest Meteorol., 122, 95-109.

Wellings, S.R. and Bell, J.P., 1980. Movement of water and nitrate in the unsaturated zone of upper chalk near Winchester, Hants., England. J. Hydrol., 48, 119-136. 